University of Nebraska - Lincoln

DigitalCommons@University of Nebraska - Lincoln

May 1993

\title{
Electronic structure of $\mathrm{Sm}_{2} \mathrm{Fe}_{17} \mathrm{~N}_{\mathrm{x}}$ compounds
}

\author{
J.P. Woods \\ University of Nebraska - Lincoln
}

A.S. Fernando

University of Nebraska - Lincoln

Sitaram Jaswal

University of Nebraska, sjaswal1@unl.edu

B.M. Patterson

University of Nebraska - Lincoln

D. Welipitiya

University of Nebraska - Lincoln

See next page for additional authors

Follow this and additional works at: https://digitalcommons.unl.edu/physicssellmyer

Part of the Physics Commons

Woods, J.P.; Fernando, A.S.; Jaswal, Sitaram; Patterson, B.M.; Welipitiya, D.; and Sellmyer, David J., "Electronic structure of $\mathrm{Sm}_{2} \mathrm{Fe}_{17} \mathrm{~N}_{\mathrm{x}}$ compounds" (1993). David Sellmyer Publications. 113.

https://digitalcommons.unl.edu/physicssellmyer/113

This Article is brought to you for free and open access by the Research Papers in Physics and Astronomy at DigitalCommons@University of Nebraska - Lincoln. It has been accepted for inclusion in David Sellmyer Publications by an authorized administrator of DigitalCommons@University of Nebraska - Lincoln. 


\section{Authors}

J.P. Woods, A.S. Fernando, Sitaram Jaswal, B.M. Patterson, D. Welipitiya, and David J. Sellmyer 


\title{
Electronic structure of $\mathrm{Sm}_{2} \mathrm{Fe}_{17} \mathrm{~N}_{x}$ compounds
}

\author{
J. P. Woods, A. S. Fernando, S. S. Jaswal, B. M. Patterson, \\ D. Welipitiya, and D. J. Sellmyer \\ Behlen Laboratory of Physics and Center for Materials Research and Analysis, University of Nebraska. \\ Lincoln, Nebraska 68588
}

\begin{abstract}
$\mathrm{Sm}_{2} \mathrm{Fe}_{17} \mathrm{~N}_{x}$ is of considerable current interest as a permanent-magnet material because of its enhanced Curie temperature and uniaxial anisotropy. The electronic structures of $\mathrm{Sm}_{2} \mathrm{Fe}_{17} \mathrm{~N}_{x}$ for $x=0$ and $x \sim 2.6$ have been studied with photoemission and spin-polarized calculations. The materials are prepared by are melting and nitrogen is introduced by ion implantation. The nitrogen concentration is quantified with Auger electron spectroscopy. The $\mathrm{Sm} 4 f$ electrons with binding energies between 6 and $10 \mathrm{eV}$ are investigated with resonant photoemission using photon energies near $140 \mathrm{eV}$. The major features of ultra-violet photoemission spectra include the Fe $3 d$ band with a strong peak at $0.8 \mathrm{eV}$ and a small peak at $2.9 \mathrm{eV}$ below the Fermi energy which agree quite well with the theoretical density of states calculation. The modification of the electronic structure with nitrogen concentration is studied to understand the effect of nitrogen addition on the magnetic properties.
\end{abstract}

\section{INTRODUCTION}

The properties required for permanent-magnet materials are a large magnetization, a large magnetic anisotropy, and a large coercivity at or above room temperature. The magnetization of a magnetic material is determined in part by the ordering or Curie temperature $T_{c}$ at which the macroscopic ferromagnetic alignment of the material is thermally destroyed. The magnetic anisotropy of superior magnetic materials is due to the anisotropic crystal structure. ${ }^{1}$ Currently, the best permanent magnet materials consist of rare-earth ( $R$ ) transition-metal $(T)$ compounds, often with a metalloid added. The compounds are generally transition-metal ( $\mathrm{Fe}$ or $\mathrm{Co}$ ) rich, which produces a large magnetization and a large Curie temperature. The addition of rare earths results in a reduced Curie temperature, but a uniaxial magnetic anisotropy is created or enhanced.

Two examples of the RT permanent-magnetic materials with widespread applications are $\mathrm{SmCo}_{5}$ and $\mathrm{Nd}_{2} \mathrm{Fe}_{14} \mathrm{~B}$. Larger transition metal concentrations are obtained in the $\mathrm{R}_{2} \mathrm{Fe}_{17}$ compounds, but these materials have low Curie temperatures and lack uniaxial anisotropy. The Curie temperature increases with the addition of hydrogen ${ }^{2}$ or carbon, ${ }^{3}$ which occupy interstitial sites. A larger increase in the Curie temperature is obtained with the addition of nitrogen $(\mathrm{N})$ into interstitial sites, and a uniaxial anisotropy is induced only when $R=\operatorname{Sm}$ (see Ref. 4).

The electronic structure of the $\mathrm{Y}_{2} \mathrm{Fe}_{17}$ compound with and without $\mathrm{N}$ was calculated with self-consistent spinpolarized calculations. The Fe $3 d$ bands near the Fermi energy shift to larger binding energies with the addition of nitrogen which is due to a reduction in overlap with increasing lattice spacing. The width of the $\mathrm{Fe} 3 d$ bands decreases, the density of states at the Fermi energy decreases, and the total magnetic moment per formula unit increases with the addition of nitrogen. These last two re- sults can be employed in the spin-fluctuation theory to model the increase in Curie temperature with nitrogenation. $^{5}$

This paper describes the electronic structure of the compound $\mathrm{Sm}_{2} \mathrm{Fe}_{17} \mathrm{~N}_{x}$ with $x=0$ and $x \sim 2.6$ as measured in photoemission experiments performed at the Alladin Synchrotron Radiation Center in Wisconsin. The $\mathrm{Fe} 3 d$ electrons dominate the photoemission spectra near the Fermi energy, with both a majority and minority peak near $1-\mathrm{eV}$ binding energy, and a second majority peak near $3-\mathrm{eV}$ binding energy. The cross section for $\mathrm{Sm} 4 f$ electron emission is enhanced due to $4 d \rightarrow 4 f$ photon absorption for photon energies near $145 \mathrm{eV}$. The final state multiplet structure of the $\mathrm{Sm}$ emission identifies the nearly $4 f^{5}$ configuration of $\mathrm{Sm}$ in the compound.

\section{EXPERIMENT AND RESULTS}

Two bulk $\mathrm{Sm}_{2} \mathrm{Fe}_{17}$ samples were used in the experiments. The first sample was prepared by arc melting Sm and $\mathrm{Fe}$ powder followed by vacuum annealing at $1000^{\circ} \mathrm{C}$ for several days. ${ }^{4}$ The second sample was prepared by arc melting $\mathrm{Sm}, \mathrm{Fe}$, and $4 \% \mathrm{Nb}$ (by weight), and the vacuum annealing stage was not required. ${ }^{6}$ The results obtained below were identical for both samples, and the $\mathrm{Nb}$ in the second sample was not detected with any experimental technique. The samples are polycrystalline with grain diameters less than $2 \mu \mathrm{m}$. A portion of each arc-melted button was pulverized into a powder and powder $\mathrm{x}$-ray diffraction verified the rhombohedral $\mathrm{Th}_{2} \mathrm{Zn}_{17}$ structure. A disc of approximately $1 \mathrm{~cm}$ in diameter and $1 \mathrm{~mm}$ thick was spark cut from each button and the surfaces were polished.

The samples were mounted on a tantalum/tungsten sample manipulator in an ultra-high vacuum chamber with a base pressure of $2 \times 10^{-10}$ Torr. $\mathrm{A}$ heating filament was 
positioned behind the samples for radiative or electron beam heating. The sample surface was cleaned with Argon ion bombardment, and the surface composition was measured with Auger electron spectroscopy (AES). The Auger and photoemitted electrons were energy analyzed with a $117-\mathrm{mm}$ radius quarter sphere energy analyzer equipped with a variable exit aperture. The photoemission experiments employed a photon energy range between 15 and $150 \mathrm{eV}$; the total resolution in the ultraviolet $(22.5 \mathrm{eV})$ photoemission experiments is $0.13 \mathrm{eV}$, and the resolution with soft $\mathrm{x}$-rays $(150 \mathrm{eV})$ is $0.50 \mathrm{eV}$.

\section{A. Nitrogen addition}

Nitrogen was introduced into the sample with ion implantation in order to maintain the ultra-high vacuum base pressure. The nitrogen ions were generated and accelerated with the same ion sputter gun used for argon sputter cleaning. The surface was initially cleaned with several cycles of argon sputtering and annealing to $350^{\circ} \mathrm{C}$, and the clean surface photoemission was acquired. The nitrogen ions were implanted with a kinetic energy of $2 \mathrm{keV}$ and a current of $6 \times 10^{-6} \mathrm{~A}$ for $10 \mathrm{~min}$. The nitrogen concentration $x$ after nitrogen sputter normalized to the formula value $\left(\mathrm{Sm}_{2} \mathrm{Fe}_{17} \mathrm{~N}_{x}\right)$ was measured with AES as $x=9.8 \pm 0.6$. The nitrogen-rich surface region acts as a source of nitrogen for diffusion in subsequent anneals to $400^{\circ} \mathrm{C}$ for several minutes. The surface nitrogen concentration is reduced to $x=3.2 \pm 0.4$ after the sample was annealed in ultra-high vacuum. The nitrogen-rich surface region is then removed with argon ion sputtering and the subsurface nitride layer was exposed. The nitrogen concentration $x$ was measured as a function of depth with argon ion sputtering and Auger spectroscopy. The subsurface nitrogen concentration was measured as $x=2.6 \pm 0.4$, and the nitride region was estimated to be $1.4 \mu \mathrm{m}$ thick. These results are similar to Kerr microscopy observations of the nitrogenation of grains by Mukai and Fujimoto. ${ }^{7}$ In their work, a surface nitrided region approximately $1.5 \mu \mathrm{m}$ thick is present in grains of $\mathrm{Sm}_{2} \mathrm{Fe}_{17}$ after annealing at $500{ }^{\circ} \mathrm{C}$ in nitrogen for one minute.

\section{B. Electronic structure}

The calculated density of states (DOS) for the clean and nitrided $\mathrm{Y}_{2} \mathrm{Fe}_{17}$ compounds are shown in Fig. 1. The self-consistent spin-polarized calculations use the linearmuffin-tin-orbitals method in the scalar relativistic approximation. ${ }^{5,8}$ The calculated eigenvalues were truncated at the Fermi energy, and then convolved with a Gaussian with a half-width of $0.47 \mathrm{eV}$ resulting in curves (e) and (f) in Fig. 1. The 2:17 DOS is dominated by two peaks at 1.0and $2.7-\mathrm{eV}$ binding energies. The $2.7-\mathrm{eV}$ peak is due primarily to majority electrons and the $1.0 \mathrm{eV}$ peak is a combination of majority and minority electrons. The main features in the $\mathrm{Y}_{2} \mathrm{Fe}_{17} \mathrm{~N}_{3}$ DOS have shifted to larger binding energies by approximately $0.3 \mathrm{eV}$, and a peak at $6.1 \mathrm{eV}$ binding energy due to nitrogen is evident.

The experimental energy distribution curve (EDC) from the $\mathrm{Sm}_{2} \mathrm{Fe}_{17}$ bulk sample obtained with $22.5 \mathrm{-eV}$ photon energy is curve (d) in Fig. 1. The surface contaminants

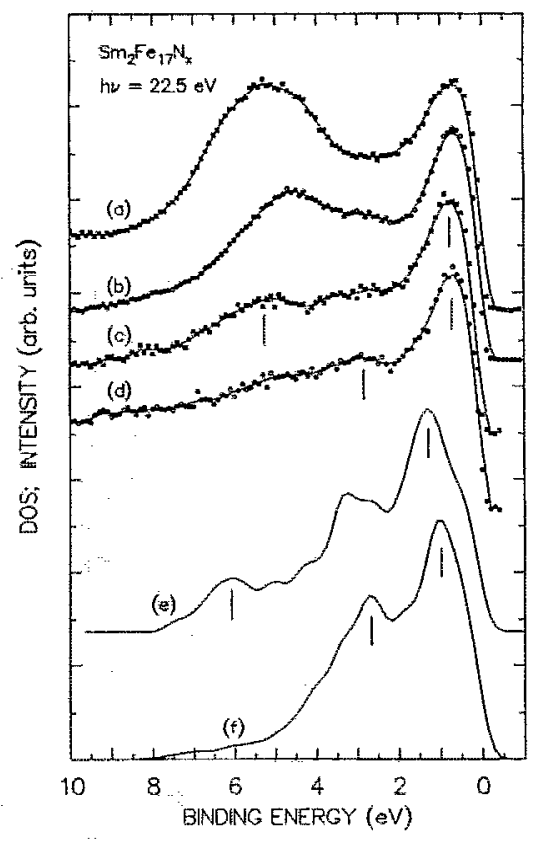

FIG. 1. Experimental EDCs and calculated DOS for the clean and nitrided 2:17 compound. The photoemission EDCs were acquired with a photon energy of $22.5 \mathrm{eV}$ and the sample was at room temperature during data acquisition. (a) EDC of the $\mathrm{Sm}_{2} \mathrm{Fe}_{17} \mathrm{~N}_{x}$ surface after sputtering with nitrogen. The nitrogen concentration is $x=9.8$. (b) EDC of the nitrogen sputtered and heated surface. The nitrogen concentration is $x=3.2$ with $12 \%$ contamination of oxygen. (c) EDC of the subsurface nitride $\mathrm{Sm}_{2} \mathrm{Fe}_{17} \mathrm{~N}_{2.6}$ obtained by argon sputtering the nitrogen rich surface layer of (b) and annealing to $350^{\circ} \mathrm{C}$. (d) EDC of the clean $\mathrm{Sm}_{2} \mathrm{Fe}_{17}$ surface obtained prior to nitrogen sputtering. (e) Calculated DOS for $\mathrm{Y}_{2} \mathrm{Fe}_{1,}, \mathrm{~N}_{3}$. (f) Calculated DOS for $\mathrm{Y}_{2} \mathrm{Fe}_{17}$.

carbon (C) and oxygen (O) are below the detection limit of AES ( $\sim 2 \%)$, and the $\mathrm{C}$ and $\mathrm{O}$ peak near $6-\mathrm{eV}$ binding energy is eliminated from the EDC. The data points are separated by $0.1 \mathrm{eV}$, and the line through the data points is a moving least-squares fit to the data. The two peaks in the EDC at 0.85 and $2.9 \mathrm{eV}$ correspond well to the peak positions in the DOS. The slope at the Fermi edge of the EDC is steeper than the calculated DOS which is due to the difference in the experimental energy resolution $(0.15 \mathrm{eV})$ and the Gaussian broadening of the DOS $(0.47 \mathrm{eV}$ FWHM).

The EDCs of various stages of nitriding the $\mathrm{Sm}_{2} \mathrm{Fe}_{17}$ $(+\mathrm{Nb})$ sample are shown in curves (a), (b), and (c) in Fig. 1. EDC (a) is from the nitrogen sputtered surface with $x=9.8$ and is most likely an amorphous surface composed of $\mathrm{Sm}, \mathrm{Fe}$, and $\mathrm{N}$ (see Ref. 9). The nitrogen peak is roughly $3 \mathrm{eV}$ wide and centered at $5.5 \mathrm{eV}$, and the $\mathrm{Fe} 3 d$ peak is slightly wider than the clean surface $3 d$ feature in curve (d). After heating to $400^{\circ} \mathrm{C}$, the nitrogen concentration decreases to $x=3.2$, and the EDC of the annealed surface taken at room temperature is curve (b). The position of the $5.5-\mathrm{eV}$ peak shifts to $5 \mathrm{eV}$ due to $\mathrm{O}$ contamination of $12 \%$ measured with AES. The Fe $3 d$ peak in curve (b) becomes sharper due to structural ordering of the surface. The uncontaminated subsurface nitride is exposed by argon sputtering and annealing, and the EDC of the nitride with $x=2.6$ in shown in curve (c). The height of the ni- 


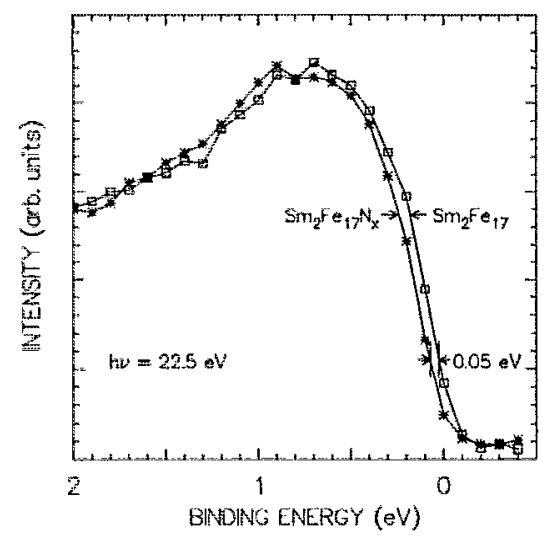

FIG. 2. Exploded view of EDCs (c) and (d) from Fig. 1 of $\mathrm{Sm}_{2} \mathrm{Fe}_{17}$ and $\mathrm{Sm}_{2} \mathrm{Fe}_{1}, \mathrm{~N}_{2.6}$. The lines connect the data points and serve as a guide to the eye.

trogen feature at $5.5 \mathrm{eV}$ is reduced relative to curve (a), and the $O$ concentration is less than $2 \%$ measured with AES. A shift $(0.05 \mathrm{eV})$ of the $\mathrm{Fe} 3 d$ peak near $0.9 \mathrm{eV}$ to higher binding energy in the nitrided EDC relative to the clean surface is shown with the vertical lines under curves (c) and (d). This shift is much smaller than the shift $(0.3$ $\mathrm{eV}$ ) in the calculated DOS.

The subtle difference between the EDCs of the clean and nitrided materials near the Fermi energy is shown in Fig. 2. The lines in Fig. 2 are through the data points and serve as a guide to the eye. The systematic shift of the EDC to higher binding energy by $0.05 \mathrm{eV}$ in the nitride is clear in the expanded binding energy scale. The reduction of the DOS at the Fermi energy of the nitride in Fig. 2 agrees with the calculated DOS at small binding energies. ${ }^{5}$

Resonant photoemission of $\mathrm{Sm}$ in the compound is shown in Fig. 3. The Sm photoemission cross section is enhanced at the $4 d$ threshold, and the EDCs above and below the threshold are shown in Fig. 3. The EDC at 135 $\mathrm{eV}$ has been scaled due to a decrease in the photon flux between data acquisitions. The $F e$ cross section will not vary sharply over the photon energy range, and the difference between the curves shown in curve (c) is due to $\mathrm{Sm}$. Below the difference curve in Fig. 3 is the multiplet structure of the trivalent $4 f^{5}$ emission $^{10,11}$ and the multiplet shifted to $0.9 \mathrm{eV}$ higher binding energy. For Sm metal, both divalent and trivalent multiplets are observed at the surface, but only a shifted trivalent configuration is observed here. The shift to higher binding energy is due to the Fe environment of $\mathrm{Sm}$, and a similar shift and valence configuration has been observed in $\mathrm{SmB}_{6}$ (Ref. 10) and SmGre materials. ${ }^{11}$ The shift to higher binding energy may be due to nonintegral occupation of the $\operatorname{Sm} 4 f$ levels, and a decreased occupation $\left(4 f^{5-\delta}\right)$ with $\delta<1$ will increase the binding energy.

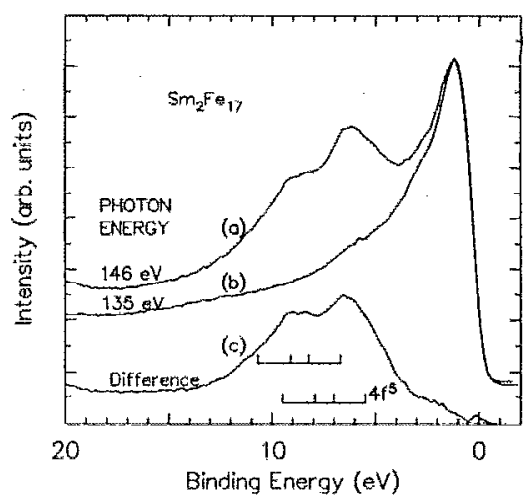

FIG. 3. Resonant photoemitted EDC of $\mathrm{Sm}_{2} \mathrm{Fe}_{17}$. (a) EDC with photon energy $146 \mathrm{eV}$, (b) EDC with photon energy $135 \mathrm{eV}$. (c) Difference between (a) and (b); (b) has been scaled by 1.08 to account for the loss in photon flux. The curves have been shifted to align the Fermi energies. The multiplet structure of the trivalent $4 f^{5}$ configuration in $\mathrm{Sm}$ metal and the multiplet shifted by $0.9 \mathrm{eV}$ are depicted below the difference curve,

\section{CONCLUSIONS}

The $\mathrm{Sm}_{2} \mathrm{Fe}_{17}$ compound surface has been nitrided in an ultra-high vacuum chamber using $N$ ion implantation and annealing. The electronic structures of the clean and nitrided compounds are calculated to be quite different, and the photoemission spectra show a subtle difference in the Fe $3 d$ electronic structure. There is experimental evidence of the decrease in the DOS at the Fermi energy upon nitriding which is consistent with an explanation of the increase in the Curie temperature of the nitrided compound. The occupation of the Sm $4 f$ levels is proposed to be $4 f^{5-\delta}$ with $\delta<1$.

\section{ACKNOWLEDGMENTS}

This work was supported by the U.S. DOE under Grant No. DE-FG02-86er45262, Nebraska Energy Office, and Cornell Supercomputing Facility. The authors thank the staff of the Synchrotron Radiation Center in Wisconsin which is supported by the National Science Foundation.

${ }^{1}$ K. H. J. Buschow, Rep. Prog. Phys. 54, 1123, (1991).

${ }^{2}$ B.-p. Hu and J. M. D. Coey, J. Less-Common Met. 142, 295 (1988).

${ }^{3}$ D. B. Mooij and K. H. J. Busehow, J. Less-Common Met. 142, 349 (1988).

${ }^{4}$ H. Sun, J. M. D. Coey, Y Otani, and D. P. F. Hurley, J. Phys.: Condens. Matter 2, 6465 (1990).

${ }^{5}$ S. S. Jaswal, W. B. Yelon, G. C. Hadjipanayis, Y. Z. Wang, and D. J. Sellmyer, Phys. Rev. Lett. 67, 644 (1991).

${ }^{G}$ A. E. Platts, I. R. Harris, and J. M. D. Coey, J. Alloys Comp. 185, 251 (1992).

${ }^{7}$ T. Mukai and T. Fujimoto, J. Magn. Magn. Mater. 103, 165 (1992).

${ }^{8}$ H. L. Skriver, in The LMTO Method, Springer Series in Solid State Sciences Vol. 41 (Springer-Verlag, New York, 1984).

${ }^{9}$ H. Hochst, A. Goldmann, and S. Hufner, Z. Phys. B 24, 245 (1976).

${ }^{10}$ J. W. Allen, L. I. Johansson, I. Lindau, and S. B. Hagstrom, Phys. Rev. B 21, 1335 (1980).

${ }^{11}$ A. Franciosi, P. Perfetti, A. D. Katnani, J. H. Weaver, and G. Margaritondo, Phys. Rev. B 29, 5611 (1984). 